Dossiê 9

Arte, Design e Artesanato: Ressignificações e Relacionamentos em Rede

DOI: $10.5965 / 25944630522021011$

\title{
ONDE O DESIGN ENCONTRA SUA DIMENSÃO LOCAL
}

\author{
Where design encounters its local dimension
}

Donde el diseño encuentra su dimensión local

Carla Paoliello ${ }^{1}$

\footnotetext{
1 Professora Auxiliar Convidada da Faculdade de Belas-Artes da Universidade de Lisboa. Possui graduação em Arquitetura e Urbanismo pela Universidade Federal de Minas Gerais (1995), mestrado e doutorado em Engenharia de Estruturas pela UFMG (2001 e 2008), e pós-doutorado pela Universidade de Lisboa na Secção de Design do Centro de Investigação e de Estudos em Belas-Artes (2016). Finalizou em 2020 seu segundo Doutoramento em Belas-Artes na Universidade de Lisboa, especialidade Design de Equipamento. Tem interesse na discussão sobre arquitetura, design, artesanato, arte, tecnologias e cultura. Lattes: http://lattes.cnpq.br/2461807641469699; Orcid: https://orcid.org/0000-0003-0186-0507; e-mail: carlapaoliello@gmail.com
} 


\section{RESUMO}

Este artigo é um resumo da tese de doutoramento 'Investigação de parâmetros de análise do design de equipamento enquanto ferramenta de impacto social' realizada em 2020 na Faculdade de Belas-Artes da Universidade de Lisboa. Trata-se de uma investigação que olhou para as questões relacionadas com o binómio design-fazer local. Para tal, produziuse uma descrição-síntese de parcerias brasileiras e portuguesas existentes nestes dois mundos (design e fazer local) e delimitou-se (descreveu-se e analisou-se) as relações provenientes e existentes neste processo com base no entendimento destas experiências. A investigação foi dividida em duas etapas. A primeira caracterizou-se por uma revisão bibliográfica que envolveu estudos de autores diversos acerca do lugar do artesanato no Brasil e em Portugal; das aproximações e diferenças do design e das suas dimensões do fazer local. Produziu- se, portanto, uma estrutura teórica a ser utilizada na segunda etapa que compreendeu a pesquisa, descrição e avaliação de 20 casos de estudo brasileiros e 5 portugueses. Foram realizadas entrevistas a partir de um questionário semiestruturado com os três atores presentes nestas parcerias - o artífice, o designer e as entidades ou instituições que fomentam estas parcerias. As ponderações finais indicam que somos todos artífices, sendo o impacto uma via com dois sentidos.

Palavras-chaves: Design; Fazer local; Encontro.

\section{Abstract}

This article is a summary of the Ph.D. thesis 'Investigating parameters for analyzing equipment design as a social impact tool' held in 2020 at the Faculty of Fine Arts, University of Lisbon. It is a research that looks at the issues related to the design and its local dimension. We produced a synthesis description of these partnerships and we delimited (described and analyzed) the different relations to understand these experiences. Two stages divided the investigation. The first characterized a literature review. It involved approaches by different authors about the place of design and local production. We also discussed the approximations and differences between these two areas. It comprised the description and evaluation of 20 Brazilian and 5 Portuguese case studies. We conducted interviews from a semi-structured questionnaire that reached the artificer, the designer and the entities that foster these partnerships. The indicators used proved to be efficient in assessing the social, cultural, economic and territorial dimensions. The final considerations state that we are all artisans.

Keywords: Design; Local Design; Encounter.

\section{Resumen}

Este artículo es un resumen de la tesis doctoral 'Investigación de parámetros para el análisis del diseño de equipos como herramienta de impacto social' celebrada en 2020 en la Facultad de Bellas Artes de la Universidad de Lisboa. Esta es una investigación que analizó cuestiones relacionadas con el binomio diseño-hacer local. Para ello, se elaboró una descripción síntesis de las alianzas brasileñas y portuguesas en estos dos mundos (diseño y hacer local) y se delimitaron (describieron y analizaron) las relaciones que surgen y existen en este proceso a partir de la comprensión de estas experiencias. La investigación se dividió en dos etapas. El primero se caracterizó por una revisión bibliográfica que involucró estudios de diferentes autores a cerca del lugar de la artesanía en Brasil y Portugal; enfoques 
y diferencias en el diseño y sus dimensiones del hacer local. Por lo tanto, se elaboró una estructura teórica para ser utilizada en la segunda etapa, que comprendió la investigación, descripción y evaluación de 20 casos de estudio brasileños y 5 portugueses. Las entrevistas se realizaron mediante un cuestionario semiestructurado con los tres actores presentes en estas alianzas: el artesano, el diseñador y las entidades o instituciones que fomentan estas alianzas. Las consideraciones finales indican que todos somos artesanos, siendo el impacto una calle de doble sentido.

Palabras llave: Diseño; hacer local; encuentro. 


\section{INTRODUÇÃO}

O atual contexto social, técnico e produtivo propicia o aparecimento de um design autónomo que concilia híbrida ou paralelamente a produção de dimensão industrial com a experimentação autoral. Aparecem novas possibilidades de atuação. Surge a figura do designer-autor, que se aproxima do craft e do modos operandi de um artesão uma vez que domina todo o processo produtivo. Surge também o designer sob a forma de consultor, externo ou integrado em equipes multidisciplinares, que descortina identidades. Entende-se o conceito de identidade como o empregado por Raul Cunca, ou seja, como "um processo contínuo de redefinir-se e de inventar a sua própria história" (CUNCA, 2019, p.23). O designer é um indutor de mais valias e busca a renovação e a atualização do seu modo de fazer e de pensar.

Tornam-se também inquestionáveis as atuais e diversas interfaces que existem entre o design e outras áreas de atuação, nomeadamente no fazer local. Por 'fazer local' entende-se como aquele conjunto de ações e, consequentemente, os produtos que são demarcados por características locais e regionais, expressão de um coletivo, de um povo, ou de um único artífice. Os objetos desta produção conseguem carregar em si as particularidades de uma cultura local.

Qual é o ponto de encontro entre o design e sua dimensão local? Como ocorre o desenvolvimento de um produto a partir da parceria que se estabelece entre designers e artífices? Estas são duas das perguntas que nortearam este texto e a tese de doutoramento 'Investigação de parâmetros de análise do design de equipamento enquanto ferramenta de impacto social' realizada em 2020 na Faculdade de BelasArtes da Universidade de Lisboa e aqui resumida.

Os encontros, em especial quando o designer trabalha em conjunto com artífices, são os objetos deste estudo. Foram analisados 25 projetos que envolvem:

- a comunidade da unidade de produção local e/ou o artífice e todo o seu contexto social, técnico, cultural e económico;

- o designer no seu papel de facilitador que, em parceria, descortina a realidade existente, a sua qualidade e beleza e que, individualmente, apresenta o seu universo; e

- as entidades ou instituições que fomentam estas parcerias e que normalmente orquestram os objetivos e metas.

Não se trata de discutir a autoria em design, mas sim de analisar como cada ator presente na parceria estabelecida mantinha e alterava o seu modo de fazer (e quem sabe de ser), ou seja, como uma expressão inicialmente própria se contaminava com a presença e expressão de um outro (figura1). 
Figura 1 - Diagrama síntese do encontro entre designers e artífices.

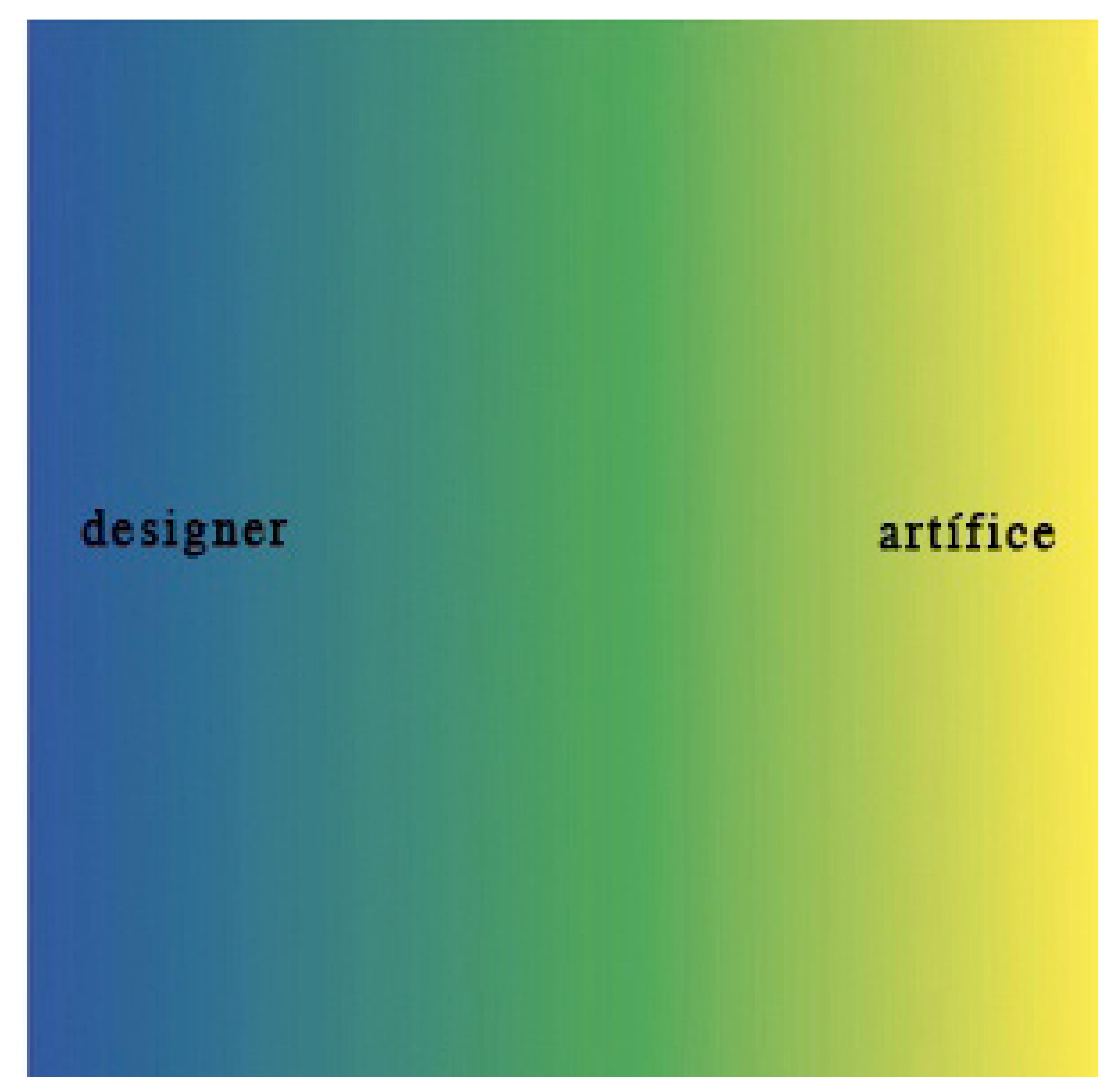

Fonte: Produção da própria autora (2020)

Desta maneira, este artigo teve como objetivo principal investigar parcerias entre designers e unidades produtivas locais brasileiras e portuguesas e como objetivos específicos: _produzir uma descrição-síntese de parcerias brasileiras e portuguesas existentes nestes dois mundos (design e fazer local); e_delimitar (descrever e analisar) as relações provenientes e existentes neste processo a partir do entendimento das experiências analisadas.

Trata-se de uma pesquisa aplicada e exploratória, ou a problem-solving research. $O$ método utilizado foi o empírico-analítico que consiste em, a partir do processo de revisão literária, análise crítica e argumentativa, apresentar e discutir os conceitos e termos da investigação. Realizou-se a análise dos casos de estudo particulares de interface entre designers e artificies que, na tese, foram descritos individualmente de maneira a compreender a realidade presente contextualizada, e aqui foram resumidos para apresentação geral das propostas. Trata-se de um método dialético, pois não se procura apenas em fazer um levantamento, mas sim refletir sobre esta realidade.

\section{DESENVOLVIMENTO}

\subsection{DESIGN \& DIMENSÕES DO FAZER LOCAL: APROXIMAÇÕES; DESIGNERS VERSUS ARTÍFICES: DIFERENÇAS}

Segundo Victor Margolin, os designers são responsáveis pelos artefactos, sistemas e ambientes que constituem o mundo social já que "o design é um acto de invenção: um processo de concepção e planeamento que pode resultar em produtos materiais ou imateriais" (MARGOLIN, 2014, p.54). Miguel Arruda, no catálogo da exposição homónima 'escultura / design / arquitetura', acredita que o design vive do encontro entre o designer, o produtor, o fabricante de materiais, o operário, etc. (ARRUDA, 2013, p.10). Já Papanek defende que "todos os homens são designers. Tudo 
o que fazemos quase sempre é projetar, pois o design é a base de toda a atividade humana" (PAPANEK, 1977, p.19) e este raciocínio foi atualizado por Donald Norman ao sustentar que "somos todos designers" (NORMAN, 2004, p.221-222). Na verdade, são inúmeras as definições existentes para esta atividade projetual.

Conceituar o artesanato também é uma tarefa difícil, uma vez que existem os que procuram defini-lo como uma atividade socioeconómica e os que a definem como uma atividade que expressa a cultura de um povo, região ou raça, fruto da criatividade, da habilidade técnica e da expressão pessoal do próprio artesão. Sabe-se que este profissional domina todas as etapas do processo de trabalho e por consequência tem consciência de sua parte no todo. Sabe-se também do seu vínculo com o produto, do significado do seu esforço e, contrariamente ao que dizem muitos textos, que fundamenta o seu fazer na associação entre teoria e prática uma vez que é impossível distanciar o trabalho intelectual do manual ou o saber do fazer.

Para entender a diferença destes dois universos, o livro 'Futuro artegiano' de Stefano Micelli foi fundamental. Nele, o autor alerta sobre a recuperação do valor cultural e económico do trabalho manual. Como Sennett, em O Artífice, ele reforça as características de busca pela qualidade primeira do trabalho executado, melhoria constante do exercício profissional (aprofundamento das técnicas), bem como o enraizamento na comunidade a partir de uma prática socialmente reconhecida.

O que se verifica é que a distância não está no fazer e no pensar, mas sim na projeção existente, ou melhor, no tempo entre o projeto e planeamento do objeto e a sua execução. Enquanto os artífices conseguem fazer as duas etapas em concomitância (prazo curto), os designers criam um espaço entre o projetar e a produção (prazo estendido), sendo comum inclusive terceirizar a produção.

Para Tim Ingold, a forma de antever do designer e do artífice também é o local de diferença uma vez que o segundo se consegue colocar "um passo à frente do material". Na opinião do autor, "não é um modo de predeterminar a forma final das coisas, mas é uma forma de abrir caminho e improvisar uma passagem. Neste sentido, antecipar é olhar através do futuro, e não projetar o futuro a partir do presente" (INGOLD, 2012, p.6, tradução livre nossa), como tradicionalmente é o projetar para o designer.

Ratificar as semelhanças e particularidades do fazer pelo viés do design e do fazer na sua dimensão local foi importante. Entretanto, mais do que definir, é fundamental conhecer os objetivos, motivações e expectativas destes dois atores quando participam numa parceria tão complexa, sem hierarquia, e colaborativa.

As diferenças e aproximações do design com o fazer local já foram pormenorizadas por diversos autores: Borges (2011), Kubrusly e Imbroisi (2011), Albino (2017), e pela própria (Paoliello, 2019, 2018, 2017, 2016). Os projetos têm o trabalhar em comum, como base.

Sennett em 'Juntos' dedica um elogio à cooperação, entendida como "uma capacidade de compreender e mostrar-se receptivo ao outro, por uma forma de alcançar um final conjunto" (SENNETT, 2012, p.9). Em algumas destas relações 
sociais, existe a tendência para um trajeto verticalizado, no qual um ator estabelece com os parceiros uma hierarquia, um poder de quem doa sobre quem recebe. Em outros casos, as relações são mais horizontalizadas e as hierarquias menos definidas. Existe a dependência, mas esta assume um carácter mútuo, fruto de uma responsabilidade coletiva pelo bem-estar de todos. O outro indivíduo é semelhante e o compartilhamento das mesmas necessidades e potencialidades faz com que juntos desenvolvam reciprocidade, num sistema no qual todos contribuem e todos recebem a contribuição de maneira aberta.

Trata-se do convite de fazer a obra com um outro, da inexistência de uma autoria única, da discussão sobre a relevância do gesto do fazer e do pensar, da avaliação dos trabalhos que se apresentam como colaborativos. Este último ponto traz em si o conceito de coletivo, de trabalho em equipa, de responsabilidade e de participação. Entretanto, vale colocar luz noutras características que também se acredita serem importantes quando se trata de trabalhos colaborativos, a saber: consciência; disponibilidade e envolvência; empatia; interesse e sensibilidade em relação à situação particular; flexibilidade; tolerância; personalidade; juízo crítico; e compromisso.

Os parceiros envolvidos nestes trabalhos passam por processos de adaptação, de metamorfose, de integração, após a vontade inicial de se estabelecer a colaboração. As pessoas se conhecem a partir do outro, se desenvolvem pelos e nos encontros, nas diferenças e nas semelhanças (processo de comparação). O outro é um obstáculo que obriga a olhar, a entender, e a admitir. Ao tomar consciência deste limite - do 'ser' e do 'outro', do 'eu' e do 'tu' -, encontra-se o 'nós' e a potência que pode existir deste encontro. Estas relações podem ser pontuais ou terem um tempo mais estendido, podem ser harmoniosas, podem tornar-se confrontos ou conquistas, o que fica como resultado é um outro processo de pensar e de fazer, mais tolerante.

Estas relações gentis foram as escolhidas como estudos de caso na nossa investigação. O foco não estava apenas na transformação formal ou técnica do objeto final, no número de participantes, ou mesmo no retorno económico conseguido a partir da nova coleção de produtos desenvolvidos. O foco estava na parceria estabelecida e na miscigenação resultante.

\subsection{O CAMINHO PERCORRIDO}

Nas primeiras observações feitas em campo, compreendeu-se o desafio de desconstruir o sentimento de inferioridade do artesão de maneira a identificar os resíduos herdados do estigma de ser tratado como um trabalhador braçal, como apenas um fazedor. Um segundo desafio consistiu em revitalizar, como já alertado por Santos, as "possibilidades histórico-culturais da herança tradicional interrompida pelo colonialismo, pela pressa, pela perda do valor cultural" (SANTOS, 2002, p.268).

Appadurai em 'Dimensões culturais da globalização' já alertava para a importância do património cultural, a manutenção da pluralidade das culturas e a ética 
global; "cultura não destaca simplesmente a posse a determinados atributos (materiais, linguísticos ou territoriais), mas a consciência desses atributos e sua naturalização com essenciais à identidade de grupo" (APPADURAI, 1996, p.27-28).

Desta forma, como acontece a troca cultural e o desenvolvimento humano? Como é possível retratar a realização do potencial de cada ser num trabalho em equipa? Como é que cada ator pode ser percebido internamente no grupo de trabalho e externamente na comunidade? Como é que a cultura de origem de cada ator envolvido é traduzida e incorporada pelos participantes? Qual a influência do ambiente, aqui entendido como território, material, técnico, e produtivo, na produção em parceria que se estabelece?

Segundo Martins (1994), o método de investigação empírico-analítico deve ser utilizado na avaliação de programas, planos, projetos ou políticas. Utilizouse também casos de estudo que, para Godoy (1995), "se caracteriza como um tipo de pesquisa cujo objeto se analisa profundamente e visa ao exame detalhado de um ambiente e de uma unidade social". Para o alcance do proposto, foram coletados dados de natureza primária e secundária, o que também classifica esta investigação como bibliográfica e de campo, em relação aos meios utilizados.

O primeiro passo da investigação foi uma procura documental com levantamento de informações em literatura de referência. O segundo passo foi a organização do instrumento de investigação para o qual foram escolhidos documentos, catálogos e sites sobre os projetos de parceria. Para compreender as dimensões das co-criações brasileiras e portuguesas foi estruturada a compilação dos projetos brasileiros e utilizada a investigação de Albino (2017). A partir dos resultados do Prémio SEBRAE TOP 100 de Artesanato e do Projeto Brasil Original, foi desenvolvida uma lista, para cada estado brasileiro, que apresenta os atores envolvidos no processo e o local em que a parceria ocorreu. Dos 27 estados federais, apenas as unidades federativas de Amapá e Roraima não estiveram presentes por não terem sido encontradas propostas do encontro design-fazer local.

A escolha dos projetos investigados com maior profundidade deu-se a partir dos seguintes critérios de seleção:

1.Serfonte de evidência de co-criação, ou seja, uma combinação respeitosa e horizontal do saber técnico-científico do design com as aptidões próprias do saber artesanal. Desta maneira, os projetos estudados estavam teoricamente enquadrados no conceito de ecologia dos saberes (SANTOS, 2002). Este primeiro critério excluía os projetos que não apresentavam com clareza a atuação de cada sujeito e a abertura para as articulações necessárias nesta complexa rede de atores e objetivos envolvidos. Nos projetos escolhidos, observam-se, com clareza, os processos de desenvolvimento de valores e de partilha cultural.

2. Ter a intenção final de serem parcerias emancipadoras (FREIRE, $1988 \mathrm{e}$ RANCIÈRE, 2002), com o interesse de resgate das técnicas, materiais e conhecimentos artesanais e a utilização das metodologias de desenvolvimento de produtos do design. Descobrir, desenvolver e dar visibilidade eram os verbos encontrados na caracterização 
dos projetos selecionados. Todos, de maneiras distintas, transcreviam estas ações nos produtos locais apresentados e na relação estabelecida entre os pares.

Estes dois filtros e o facto de terem sido escolhidos projetos a partir de 1998 - data desde a qual houve um incentivo maior do governo brasileiro no desenvolvimento destas ações - culminou num número elevado de parcerias (247, no caso brasileiro e 40, no caso português), o que demostra claramente o interesse e incentivo pelas práticas de diálogo entre design e o fazer local.

A partir destes foram considerados os que melhor contribuíam na avaliação do impacto: na qualidade de vida e cultura dos envolvidos, no aumento de maisvalia ao produto ou serviço prestado; e na potencialização de uma vivência mais intensa do território. Os indivíduos (designers, artífices, entidades) foram considerados simultaneamente seres singulares e membros da comunidade de maneira a nutrir tanto as singularidades quanto a experiência coletiva dos sujeitos envolvidos. A situação ideal envolveria a imparcialidade; a expectativa de que os participantes transcendam as suas preferências ou receios iniciais; a inclusão de todos os afetados pela parceria; a igualdade, liberdade e facilidade de interação, com as ausências de formas internas e externas de coerção; e a clareza e visibilidade dos resultados.

Alguns impedimentos, porém, já haviam sido previstos como o tempo (prazo da investigação); a cultura do medo, da insegurança e da culpa (potencial de responsabilização); o orgulho e a relutância em se avaliar ou autoavaliar (exposição das falhas ou erros); ausência de indicadores consensuais (uma vez que o questionário foi formulado apenas pela pesquisadora e não em conjunto com os atores participantes); dificuldade em ser realizado devido à distância e não envolvimento de algumas partes. A investigação foi adaptada, de maneira a considerar cada realidade na sua totalidade e cada força (individual) que altera o grupo (realidade existente).

Por fim, a amostra investigada consistiu em 20 projetos brasileiros e 5 portugueses. Vale mencionar que tanto o Brasil quanto Portugal são países com regiões geográficas complexas, dentro das quais se distinguem paisagens culturais diversas. O Norte não é igual ao Sul, a costa também difere do interior e o fazer quando local representa esta diferença na matéria-prima utilizada e técnica empregada, nos seus valores e recursos. Além disso, as parcerias são sempre encontros resultantes dos atores que ali estão presentes, das suas histórias e intenções.

De forma resumida e sistemática, foi possível: conhecer a realidade e a relação desenvolvida; e delimitar o objeto (definição dos termos da parceria, dos atores envolvidos, do tempo e escopo do trabalho).

\section{OS ESTUDOS DE CASO E AS SUAS PARTICULARIDADES}

Expor cada projeto de parceria design-fazer local é falar de um conjunto de características próprias que se concentram na localidade e nos sujeitos das parcerias. É falar também de diferentes modos de fazer e de criar. É dar vista ao património cultural, ambiental, material e imaterial, a saberes muitas vezes intangíveis que surgem 
na pluralidade do encontro, no exercício de mediação da troca, nos interstícios entre o designer e o artífice.

A intangibilidade muitas vezes materializa-se nos produtos desenvolvidos, numa ação conjunta de reconhecimento e valorização de uma produção autêntica, portadora de uma identidade de procedência. Um produto resultante do fazer local destaca-se pela utilização de materiais e técnicas predominantes na região. Ele pode ter motivos tradicionais, religiosos ou étnicos e pode resgatar a memória histórica, técnica ou económica. Do encontro pode haver uma melhoria no processo como um todo, desde a produção até à comercialização final, normalmente com o redesenho da cadeia produtiva ou do arranjo produtivo local, além da minimização dos custos.

Nos casos estudados, verificou-se a transformação social e humana, com melhoria na distribuição de renda e de bem-estar e com a diminuição da migração da localidade para outras, nomeadamente para os grandes centros urbanos. Havia o respeito pelas devidas competências e valores. São 25 projetos que reafirmam a identidade de quem produz, valorizam os profissionais participantes, melhoram a qualidade dos produtos e promovem o resgate cultural e o desenvolvimento local.

Nestes encontros houve a construção de um outro modo de engajamento, como explicado por Santos, através da articulação das "estruturas do saber moderno/ científico/ocidental com as formações nativas/locais/tradicionais de conhecimento" (SANTOS, 2006, p.540). São formas de diálogo e de emancipação.

Vários dos projetos escolhidos foram articulados pelo SEBRAE e CEARTE, entidades brasileira e portuguesa que auxiliam comunidades na descoberta, valorização e utilização do design como estratégia de desenvolvimento sociocultural. Outros, de cunho e tempo académico, também foram selecionados, além dos financiados por entidades privadas. Procurou-se abranger o panorama de maneira a ampliar os exemplos de cooperação existentes. Procurou-se também apresentar a riqueza e a variedade cultural e material que existe nos $8.516 .000 \mathrm{~km}^{2}$ de área territorial brasileira a partir da seleção de projetos em unidades federativas diversas deste país e nos $92.212 \mathrm{~km}^{2}$ do território de Portugal, de maneira a evidenciar suas diversas regiões.

A diversidade identificada nos projetos conduziu a identificação de alguns fatores que permitiram organizar a complexidade da rede de informações estudada. $A$ maneira de agrupar os projetos ocorreu a partir da figura do 'agente de fomento' da parceria. Por fomento entende-se o estímulo. Desta maneira, o agente de fomento é aquele ator que incita, articula e busca o apoio para a realização da parceria. Estes podem ser traduzidos nas figuras dos artífices (artesãos ou associações de artesãos), dos designers (individualmente ou em grupo) e das entidades (faculdades, associações industriais, instituições públicas, fundações, institutos, ONG, etc.). Pretendeu-se conhecer esta realidade multilateral com consciência.

A partir do conhecimento do 'agente de fomento' de cada convergência a ser citada, criou-se quatro narrativas: 'Início pelo fazer local', 'Começo pelo Design', 'A partir de uma entidade' e 'Com fundamento académico'. 


\subsection{INÍCIO PELO FAZER LOCAL}

Ao revisitar o livro 'Tempos de grossura: o design no impasse' de Lina Bo Bardi, pode-se afirmar que não existe artesanato no Brasil, o que existe é uma disponibilidade imensa para o fazer. Fazer este que é local, que surge por sobrevivência ou por necessidade e tem disposição e vontade de evoluir. Já em Portugal, este é compreendido como a arte do fazer tradicional, repassada ao longo do tempo por atores sociais ou institucionais do território. Segundo Albino, ele é o "conhecimento tácito intergeracionalmente transmitido, incluindo aqui, naturalmente, o próprio artesão, o produto desse conhecimento e os serviços que lhe são associados" (ALBINO, 2017, p. 19).

Independentemente do conceito, considera-se aqui aquele fazer que é parte integrante do quotidiano e dos costumes dos seus produtores. O fazer que constrói e significa os territórios. Os artífices deste fazer possuem como atitude uma alta inventividade, buscam particularidades e reflexões nos seus contextos de produção e uma abertura incansável para o desenvolvimento pessoal, técnico e económico. Situam-se num processo contínuo de maneira a ter mais qualidade e mais autenticidade. Um processo que reafirma o seu modo de vida e reverbera a sua cultura e as suas dimensões simbólicas e identitárias. Desta maneira, este fazer não pode ser percebido somente desde a análise do artefacto isolado, deve-se considerar as questões sociais e históricas de cada comunidade. Deve-se também entender que a procura pela inserção de inovações na cadeia produtiva facilita a sua necessária inserção no mercado para assegurar a sua reprodutibilidade, ainda que num estado alterado da tradição.

Quando estes, como os casos de Espedito Seleiro, Doutor da Borracha e das artífices da Cooperativa Bordana e das Capuchinhas de Montemuro - exemplos deste item - figura 2 -, buscam a aproximação com o design, sua cultura material e imaterial é reconceitualizada. As trocas refletem o próprio intercâmbio de experiências e a partilha de visões de saber-fazer, ora próximos e ora distintos, que moldam a continuidade do património.

Os artífices buscam instrumentos para definirem estratégias de singularização, de apropriação do sentido simbólico dos seus produtos e de autonomia para melhor assumir a propriedade dos meios de produção, de divulgação e de distribuição. Não se trata de uma procura de um aprimoramento técnico, apesar de que em alguns casos isso possa também acontecer, mas prioritariamente de ir ao encontro e reforçar uma conduta estética, artística, subjetiva, emotiva e simbólica. Nos quatro exemplos desta narrativa, é inevitável ver a (re)tradução da identidade territorial e o processo por meio do qual os artesãos passam a interpretar os seus próprios sistemas de referência. Não Ihes interessa apenas buscar a solução, adaptar, melhorar ou inovar; existe a latente necessidade de significar, de representar, de expressar, resultante do intercâmbio com outra área do conhecimento (o design). Vale ressaltar que os encontros aqui ilustrados se pautam pela complementariedade de 
saberes e práticas (científicas e não científicas) e promovem elementos mobilizadores e impulsionadores de geração de renda e bem-estar.

Figura 2 - Peças da coleção 'Meu coração Coroado' do artífice Espedito Seleiro com o designer Érico Gondin, Nova Olinda, Ceará, BR / Sandália do artífice Doutor da Borracha com a designer Mazarelo de Miranda, Reserva Extrativista Chico Mendes, Acre, BR / Cortina da coleção Arranjo produtivo das artífices da Cooperativa Bordana com o designer Renato Imbroisi, Goiânia, Goiás, BR e Peça produzida pela Cooperativa Capuchinhas com a designer Helena Cardoso, Campo Benfeito, Castro Daire, PT.


Fontes: SEBRAE-CE - http://artesol.org.br/rede/membro/doutor_da_borracha - http://www.artesol.org.br/rede/membro/ cooperativa_bordana - https://capuchinhas.blogspot.com/

\subsection{COMEÇO PELO DESIGN}

A segunda narrativa apresentada é aquela em que as ações se iniciam a partir do designer. Nestes casos, o design aproxima-se da ciência do incerto de Dilnot ou dos conceitos de hibridez e mimetismo de Bhabha. No seu livro, 'The Location of Culture', o autor apresenta os espaços entre-culturas, intersticiais ou in between. Ele coloca questões sobre identidade, olhar duplo, desterritorialização (displacement) e o intraduzível termo unhomeliness, um sentimento de não ter lugar certo.

O encontro design e fazer local posiciona ambos atores neste lugar de retirantes de uma cultura para a abertura ao outro saber. É um lugar de transferência, de "encontro entre sujeitos interlocutores que buscam a significação dos significados" (FREIRE, 2011, p. 46), de fluxo e troca, de relação com a criação, a produção, distribuição e a demanda. Não estava nos objetivos dos estudos de caso estudados a realização da instrução científica dos artífices por meio de um especialista. De modo contrário, entende-se que a proximidade com os artífices posicionou o designer no mercado a partir dos aspetos identitários territoriais. O local é o espaço suporte da experiência, de uma produção mais autóctone, relacional e contextual e, em alguns casos, com grande referencial histórico. É porque os valores simbólicos são alterados além dos modos de fazer, de lidar com os recursos locais e com o tempo. Preservase, no entanto, o domínio em todo o ciclo produtivo e a inseparabilidade da atividade criativa do processo de produção.

Para ilustrar esta narrativa, foram apresentados o olhar e a abordagem da designer Maria Fernanda Paes de Barrosem em três casos distintos; da designer Marta Martins da Ecoarts em parceria com a Vista Alegre; de Jackson Araujo e Luca Predabon com os designers Alexandre Herchcovitch, Itiana Pasetti e Marcelo Rosenbaum que trazem o conceito de economia afetiva; e de Susana António à frente da iniciativa portuguesa A Avó Veio Trabalhar (figura 3). Que seja reconhecida a diversidade que 
une e a construção em conjunto, uma vez que "ambos são formas de procurar entender e agir sobre o mundo. E ambos são também obras abertas, inacabadas se fazendo constantemente" (CUNHA, 2009, p. 302).

Figura 3 - Luminária Pezinho da designer Yankatu com a artífice Zana Maria, Muzambinho, Minas Gerais, BR / Conserveira da designer Marta Martins com as artesãos associadas à Ecoarts, Fazenda Vale do Sonho, Mato Grosso, BR /Luminária NI de mesa da designer Yankatu com a artífice Deuzani Gomes dos Santos, Coqueiro Campo, Vale do Jequitinhonha, Minas Gerais, BR / Banco Palafitas tradicional da designer Yankatu com a Comunidade artesã de Urucureá, Pará, BR / Almofalange dos designers e artífices do Projeto Trama Afetiva, São Paulo, BR / Exemplar da coleção de almofadas da designer e artífices d’A Avó Veio Trabalhar, Lisboa / PT.

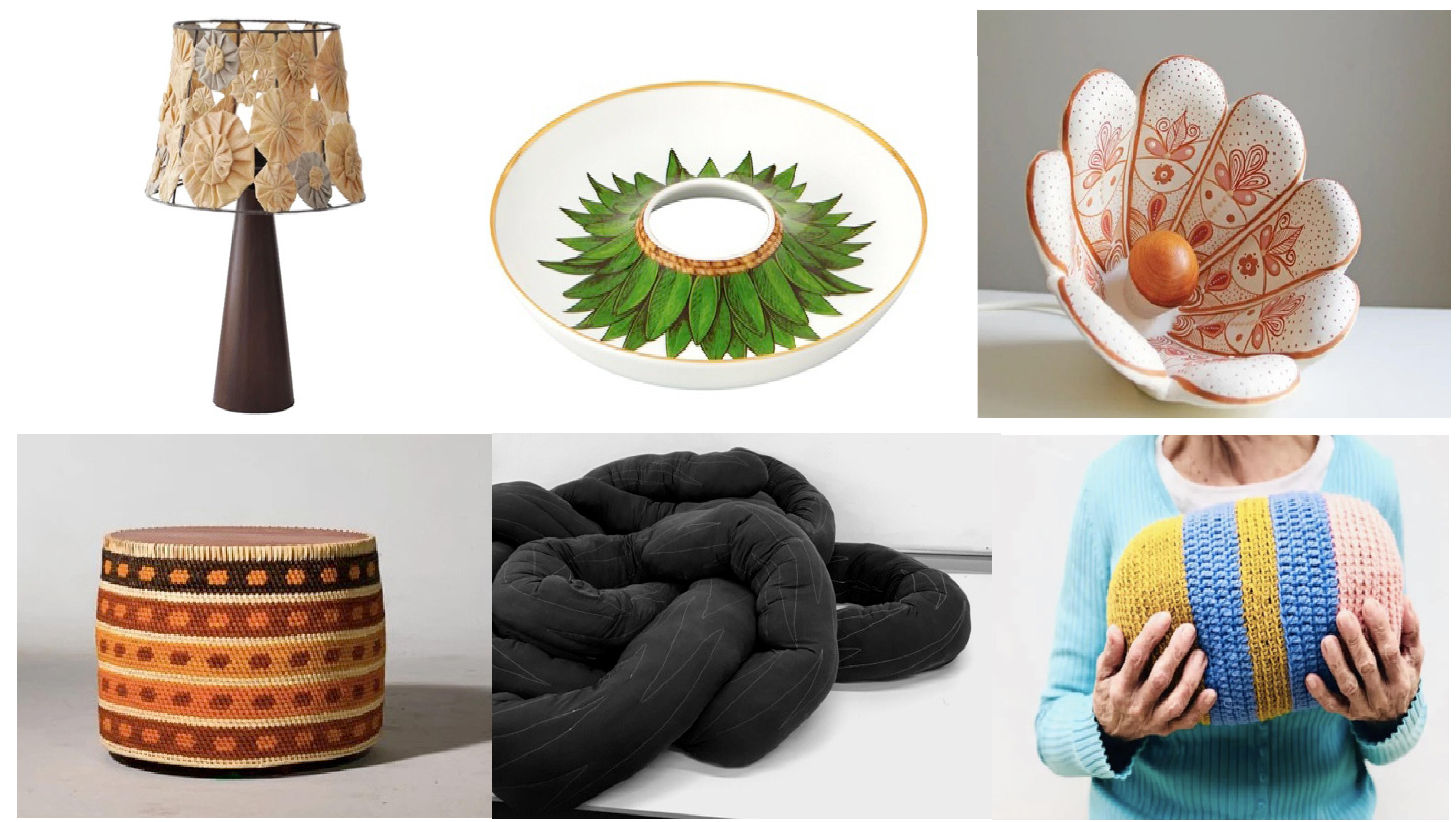

Fonte: https://www.yankatu.com.br/ipe - https://www.yankatu.com.br/registros-do-tempo - https://www.yankatu.com. br/alma-raiz - https://vistaalegre.com/pt/amazonia-conserveira-21133546-pt - http://fundacaohermannhering.org.br/img/ publication/publicacao-economia-afetiva-um- aprendizado-para-o-futuro-por-fundacao-hermann-hering.pdf - Acervo $A$ Avó Veio Trabalhar.

\subsection{A PARTIR DE UMA ENTIDADE}

São diversas as iniciativas, instituições e entidades que buscam fomentar o encontro do design com o fazer local e possibilitam o diálogo entre os saberes científicos e os tácitos. Entendem esta parceria como um vetor para os processos de desenvolvimento territorial com base em especificidades culturais. Alguns dos projetos trabalham de maneira a salvaguardar os saberes tradicionais e evitar o desaparecimento de técnicas tradicionais; ou a desenvolver propostas que visam uma maior inserção no mercado com impacto socioeconómico para os envolvidos; ou dar maior visibilidade e prestígio aos artefactos produzidos; ou mesmo a aumentar o sentido de pertença da comunidade com o conhecimento e perceção do valor sobre do seu saber-fazer.

Vários estudos evidenciam a assimetria existente nas relações de poder que permeiam algumas destas parcerias. Canani alerta para o facto de não se tratar, portanto, de

um caso de apropriação pela elite de uma expressão da cultura popular, já que verificamos que a prática artesanal é fomentada nas localidades por instituições com interesses específicos, por meio de políticas públicas de incentivo, e não expressão artística realizada 
com fim em si mesma, embora em alguns casos isso também possa estar presente nessa atividade. (CANANI, 2008, p. 262).

Apresenta-se aqui apenas os projetos nos quais houve a desconstrução das questões de poder e autoridade e o entendimento de que ambos possuem conhecimento, sensibilidade e consciência no seu fazer, para assim retratar uma ação conjunta e híbrida de criação de um produto. Esperou-se o estabelecimento do comum, do partilhável, e também do desenvolvimento de uma autonomia futura de todos os envolvidos no processo.

Trabalhou-se com projetos iniciados pelas entidades públicas: SEBRAEPI, SEBRAE- AM, SEBRAE-TO e Secretaria de Cultura do Estado de Tocantins, SEBRAE-RS, SENAR, EMATER e Fibria, SEBRAE-MG; e Câmara Municipal de Loulé e pelas entidades privadas: Instituto Supereco, Instituto Elos e Campana (Figura 4).

Figura 4 - Cesto da coleção Toca da Palha da Associação das Mulheres Artesãs de Várzea Queimada com o designer Marcelo Rosenbaum, Piauí, BR / Luminária Kuripako dos artífices das regiões ribeirinhas do Amazonas com o designer Sérgio Matos, Amazonas, BR / Peça do Catálogo 'Ouro Vivo' dos artífices do povoado do Mumbuca com o designer

Renato Imbroisi, Parque Estadual do Jalapão, Tocantins, BR / Casulos dos artífices da Capitania das Fibras com a designer Mazarelo Carneiro de Miranda, Capitão Enéas, Minas Gerais, BR / Jogo Resta 1 da coleção Bichos do Mar de Dentro dos artesãos do projeto Artesanato do Mar de Dentro com equipe liderada por Renato Imbroisi, Costa Doce, Rio Grande do Sul, BR / Fruteira Renda da Associação Arte Helvécia com a designer Paula Dib, Bahia, BR / Colheres da Associação dos Jovens da Jureia com as designers Paula Dib e Renata Mendes, São Paulo, BR / Banco Black Power dos artífices do Projeto Arrastão com os designers Campana, São Paulo, BR / Workshop de cerâmica dos artífices do Loulé Design Lab com o designer Henrique Ralheta, Loulé / PT.

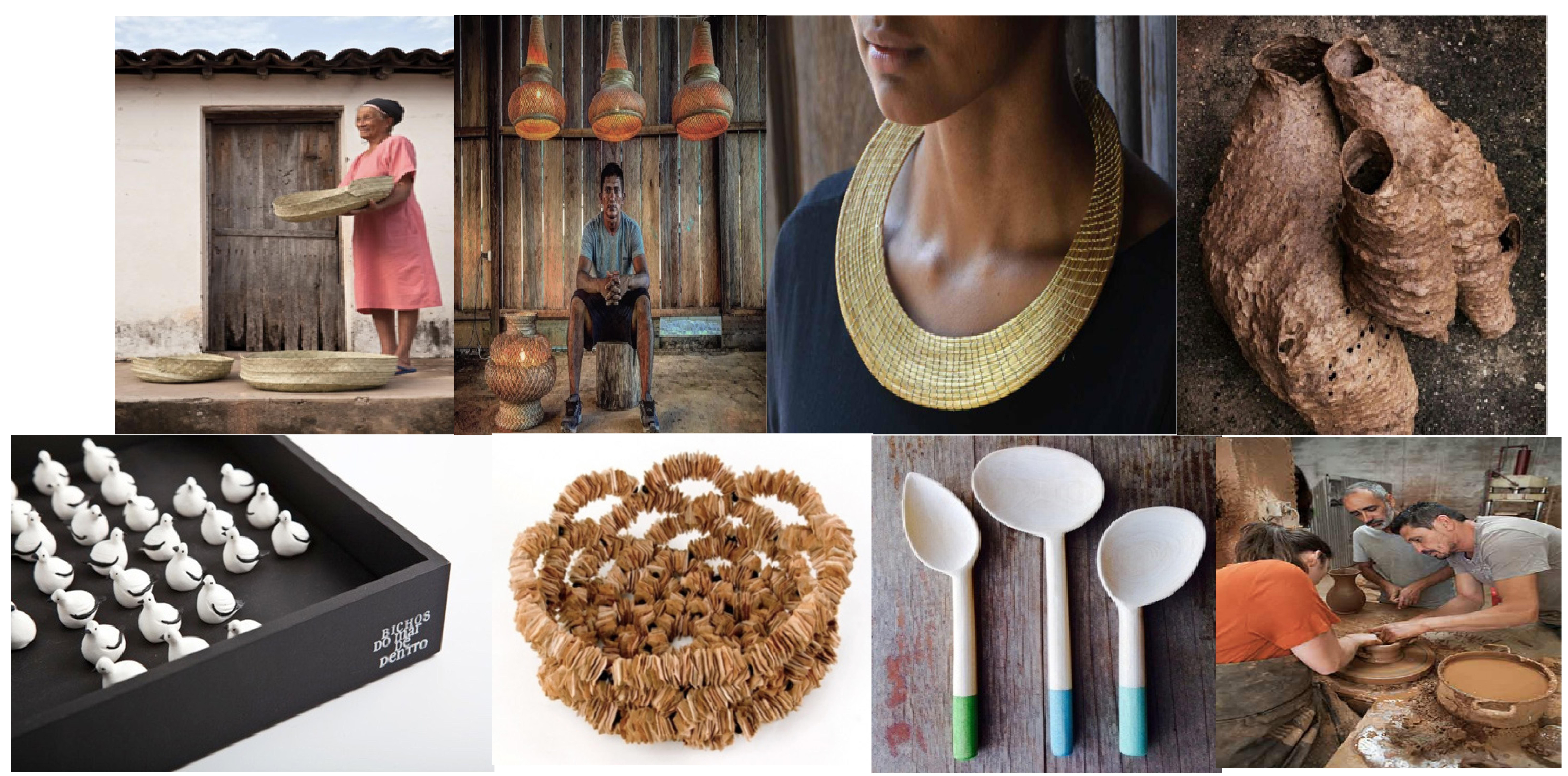

Fonte: http://www.tecto.com.br/Noticias/2012/08/07/Varzea-Queimada--no-Piaui - http://www.artesol.org.br/conteudos/ visualizar/O-design-da-floresta2 - SEBRAE-TO - http://www.artesol.org.br/rede/membro/associacao_bichos_do_mar_ de dentro - www.facebook.com/capitaniadasfibras - http://www.acasa.org.br/reg_mv/OB-00892/25b2115b2d $\overline{1} b 23 \mathrm{cb} 4 \overline{9}$ bd8343182d2f76c - https://www.institutocampana.org.br/projeto-arrastao - https://www.barlavento.pt/destaque/louledesign-lab-vai-transformar-instalacoes-do-antigo- inuaf-em-laboratorio-criativo

\subsection{COM FUNDAMENTO ACADÊMICO}

Nas universidades, em especial as brasileiras, existe a procura pela interação entre o ensino, a pesquisa e a extensão. Compreende-se que estes campos distintos têm práticas comuns que resultam num processo contínuo de formação de 
sujeitos a partir das interações sociais, históricas e culturais. No caso específico das práticas extensionistas universitárias, ocorre o reforço da contribuição académica para a região na qual esta está locada; a atuação e participação na comunidade através de projetos sociais ou de parcerias firmadas com os órgãos públicos, empresas e outras organizações.

A participação dos professores como orientadores e elaboradores de propostas de extensão permite o aprofundamento das questões discutidas em sala de aula com um ponto de vista teórico indissociado do prático. Verificou-se nos casos estudados o empoderamento dos alunos enquanto atores de mudança em campo que atuam no encontro de soluções para os problemas locais e de interesse da comunidade. A produção do conhecimento é realizada através dos serviços prestados à coletividade, do fortalecimento da formação humanística e do desenvolvimento de competências sociopolítica, técnica e prática.

Como na narrativa anterior, nestes projetos acontece também a desconstrução do poder. O professor, o aluno e o artífice são todos sujeitos colaboradores que trabalham em parceria na criação ou melhoria de um produto. Cada um reconhece o seu saber-fazer e está aberto à contaminação pelo outro.

Os projetos 'com fundamento académico' aqui analisados foram os desenvolvidos pel'O Imaginário da Universidade Federal de Pernambuco, o da Universidade Federal do Maranhão, do Centro Universitário do Leste de Minas Gerais, do Instituto Politécnico de Castelo Branco e o do CEARTE com a Agência para o Desenvolvimento Turístico das Aldeias do Xisto (Figura 5).

Figura 5 - Peça do mestre Nena e designers d'O Imaginário, Pernambuco, BR / Vaso das artífices de Itamatatiua com a designer Raquel Noronha e alunos do curso de Design da UFMA, Maranhão, BR / O trançar da palha com a artífice da comunidade de Cocais das Estrelas, designer Carla Paoliello e alunos do Unileste, Minas Gerais, BR / Trabalho com a polpa desenvolvida a partir das fibras do tratamento primário com o Grupo de Artesãs de Cachoeira Escura, a designer Carla Paoliello e alunos do Unileste, Minas Gerais, BR / Tábua para travia de Joana Santos aluna participante do projeto Designesart do designer Raul Cunca, Castelo Branco, PT / 'Pedra sobre Pedra' de Joana Silva Moreira e Hugo Cardoso alunos participantes do projeto Agricultura Lusitana do designer João Nunes, Aldeias do Xisto, PT /
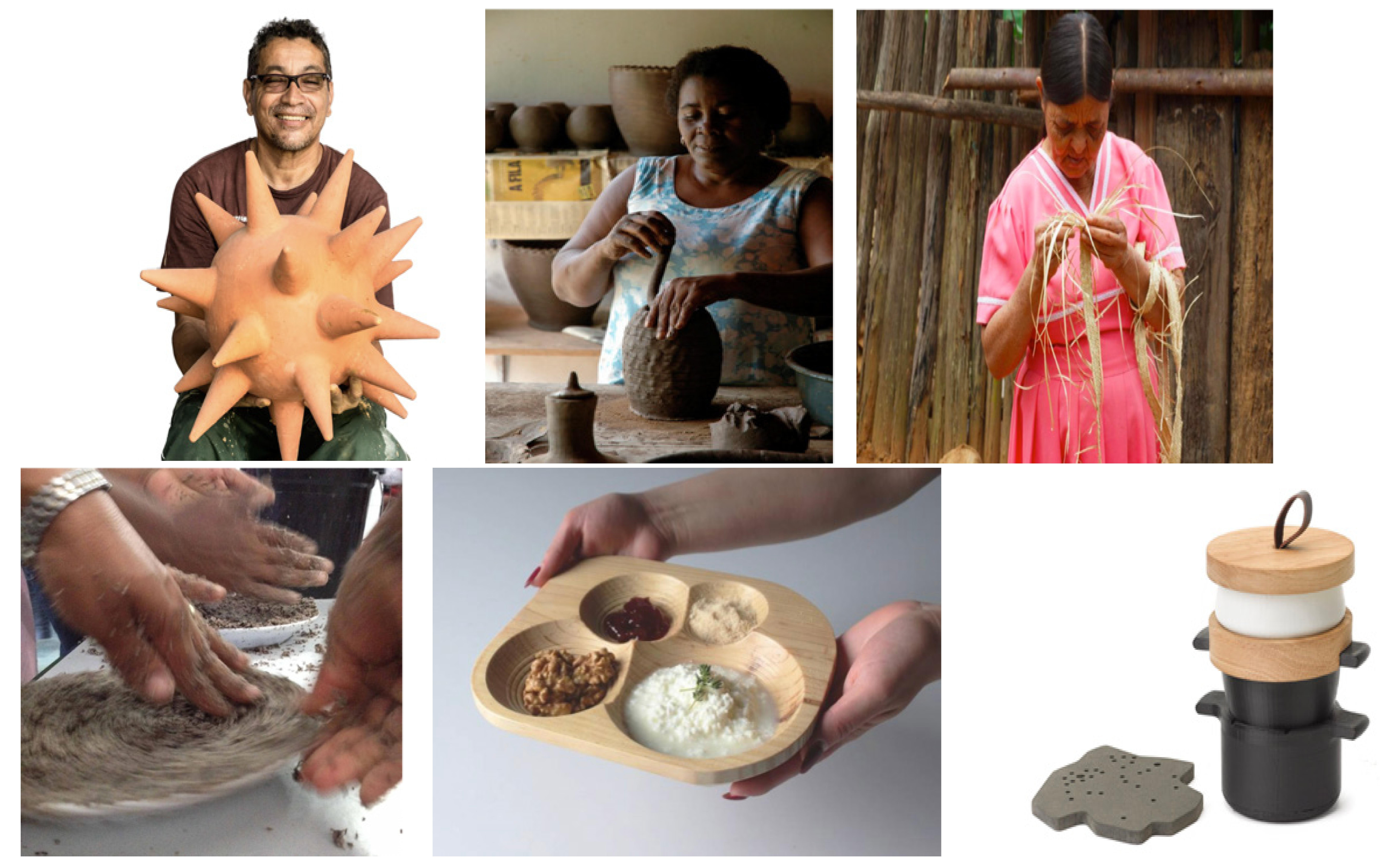

Fonte: http://www.ceramicadocabo.com.br/mestrenena/ - https://www.flickr.com/photos/marcelosoares/39903828862/ própria autora - http://artesanatoparacachoeiraescura.blogspot.com/?view=magazine - https://www.facebook.com/ projectesart/photos/ - https://www.thegentleman.pt/2017/04/aldeias-xisto-exposicao/ 


\section{ANALISAR AS PARTICULARIDADES EM BUSCA DO COMUM E AS CONSIDERAÇÕES FINAIS}

No item anterior, foram brevemente descritos 25 encontros do design com a sua dimensão local. Ao serem analisados como um conjunto, fica claro que estes casos partilham características comuns:

_ Todos se referem, por escolha, a iniciativas que envolvem um artífice ou uma unidade de produção local e o seu contexto social, cultural, simbólico, económico e ambiental; um profissional ou uma equipa coordenada por um designer e as suas práticas metodológicas, técnicas e simbólicas e as entidades ou instituições que fomentam estas parcerias.

_Existe o interesse em salvaguardar o saber-fazer dos envolvidos, além de renovar o modo de ser e pensar de cada ator. Existe também o respeito pela diversidade cultural; a indução de mais-valias e o fortalecimento da identidade local. Houve a promoção de bem-estar e a melhoria da qualidade de vida; além de desenvolver sócio e economicamente o grupo produtivo.

Entendeu-se que o fazer é parte integrante e indissociável da vida quotidiana, o que favorece a troca de conhecimentos, e que o projetar com e o uso de metodologias de co-criação reconhece cada sujeito, cada história e cada saber. Todos os casos de estudo apresentam uma componente coletiva colaborativa, com princípios explícitos de solidariedade e democracia.

_Alguns dos casos refletem mais efetivamente a ligação entre tradição e inovação e, em todos houve a constituição e o empoderamento de uma rede formal e/ou informal de produção, comercialização, divulgação e distribuição com o aumento da visibilidade do projeto e da coleção desenvolvida.

_Evidenciou-se o sistema de apoio utilizado, que atua no sentido de promover e despertar 'vocações' empresariais desde o arranque do negócio, com formação, informação e aconselhamento, até o apoio financeiro ou de melhoria de infraestrutura. As ações faziam-se sempre de maneira a promover a emancipação e desenvolver capacidades próprias de gestão.

_Por fim, verificou-se em todos que o pensamento parte da cartografia geográfica, social e cultural na qual não existe separação entre as pessoas inseridas no processo de produção e a localidade a qual elas pertencem. Reconheceram-se materiais e técnicas locais considerados património material e imaterial. Vale ressaltar que muitas das áreas nas quais estão os projetos estudados possuem escassas oportunidades de emprego e risco de despovoamento e que, nas parcerias estudadas, existia a vontade de desenvolvimento local com a sustentabilidade dos territórios, mesmo que em pequena escala.

Entretanto, nem todas as atividades artesanais são narrativas tradicionais e geracionais (como no caso do Trama Afetiva, Artesanato do Mar de Dentro, Capitania das Fibras, Associação dos Jovens da Juréia, Projeto Arrastão, alguns dos projetos do Loulé Design Lab e do Designesart, do Grupo de Artesãs de Cachoeira Escura 
e do projeto Agricultura Lusitana). Não obstante, em todos: a memória, as crenças compartilhadas socialmente e a perceção territorial foram ativadas como componente simbólico nas coleções idealizadas. Canani inclusive já havia afirmado que "os mitos e as representações que compõem o universo do artesanato são as balizas que ao mesmo tempo permitem um certo movimento enquanto conformam as ações dos sujeitos envolvidos, por meio das negociações de significados" (CANANI, 2012, p. 155).

Em alguns dos casos (como o dos Artífices de Itamatatiua e da Comunidade Artesã de Urucuerá) o fazer era o meio de subsistência das famílias locais, em outros (Associação de Capim Dourado Pontealtense e Artífices da comunidade de Cocais das Estrelas) era uma renda complementar, ou até mesmo uma ocupação sem fins lucrativos, tendo-se depois tornado numa fonte de renda (Artesãos do projeto Artesanato do Mar de Dentro) ou de 'felicidade' (Artífices d'A Avó Veio Trabalhar).

$O$ acesso ao crédito ou a programas de incentivo viabilizou a melhor estruturação e o crescimento da atividade como foi o caso do Centro de Artesanato do Cabo - Arquiteto Wilson Campos Júnior e do Doutor da Borracha, dentre outros. Inevitável também pensar que a presença da atividade turística contribui para o maior desenvolvimento do fazer local como o é para Espedito Seleiro, as Capuchinhas de Montemuro, a Associação das Mulheres Artesãs de Várzea Queimada, a Associação de Capim Dourado Pontealtense, os artífices de Itamatatiua e o projeto Agricultura Lusitana.

A disponibilidade de matéria-prima local é um fator que também contribui para o desenvolvimento como foi o caso das artífices do Grupo de Artesãs de Cachoeira Escura, da comunidade de Cocais das Estrelas, de Itamatatiua, do Projeto Arrastão, do Projeto Trama Afetiva, das regiões ribeirinhas do Amazonas, no Centro de Artesanato do Cabo; das associações Arte Helvécia, de Capim Dourado Pontealtense, dos Jovens da Juréia, e das Mulheres Artesãs de Várzea Queimada; da Comunidade Artesã de Urucuerá, com Deuzani Gomes dos Santos; com Zana Maria; as Capuchinhas de Montemuro; o Doutor da Borracha e Espedito Seleiro.

Por fim, e como já classificado anteriormente, alguns projetos foram criados por iniciativa da própria comunidade, outros pelo olhar do designer e outros por iniciativa do governo como política pública de crescimento económico e desenvolvimento local. Na grande maioria dos casos (19 dos 25 analisados), o governo e outras entidades público ou privadas tiveram um papel relevante para o desenvolvimento dos projetos, motivação da comunidade e reestruturação da produção e da sua comercialização. Apenas as três ações propostas pela Yankatu, o da ECOARTs e o proposto pela Cooperativa Bordana foram "financiados" pelos próprios integrantes.

Constatou-se que cada localidade é única, com paisagem e tradição particular. Cada unidade produtiva é específica e apresenta os seus próprios desafios, recursos e potenciais. Cada rede de colaboração se organiza de maneira própria, apesar de todas estarem implicadas no desenvolvimento humano e local. As novas circunstâncias de mercado possibilitam a criação de um novo paradigma económico (pequenas unidades produtoras locais) e organizacional (processos colaborativos). 
É claro que isso só se torna possível por haver uma determinada demanda, ou seja, por existir um nicho de mercado com interesse e consciência para os produtos resultantes das propostas locais. Entretanto, além disso, é fundamental a criação e a continuidade de políticas públicas de apoio a estas regiões no que diz respeito à rede de transporte para escoamento da produção; locação de recursos para a criação de um ambiente empresarial, legal e fiscal favorável; ampliação do sistema de saúde e de segurança para os habitantes de maneira a evitar a migração; e o acesso ao capital e a créditos especiais para o desenvolvimento das microempresas.

Não foi percebida grande diferença entre os casos brasileiros e os portugueses. Em ambas as culturas, foi possível aferir o resultado das parcerias que é o desenvolvimento social, cultural, ambiental, e económico de todo o grupo envolvido além do resgate da importância do encontro de saberes e de identidades. Valorizase o design, o fazer local e o território a partir da colaboração.

Por fim, pode-se afirmar que a principal contribuição da presente investigação foi a de entender que somos todos artífices (figura 6 ). 0 designer pode transformar, modificar um outro, mas também ele próprio se altera e desenvolve. O impacto é uma via de dois sentidos. A postura colaborativa nestes processos de criação participativos, responsáveis e bilaterais não só é uma característica necessária como se torna essencial. A abertura para o intercâmbio dentre as diversas áreas do conhecimento e na complementaridade de práticas (científicas e não científicas) propicia o diálogo de saberes e ressignifica o mundo para fazê-lo melhor. Para ser melhor, continuamente ${ }^{2}$.

Figura 6 - Todos somos artífices.



Fonte: Produção da própria autora (2020)

\section{REFERÊNCIAS}

ALBINO, Cláudia. À Procura de Práticas Sábias. Design e Artesanato na significação dos Territórios. Coimbra: CEARTE, 2017.

APPADURAI, Arjun. Dimensões culturais da globalização. Lisboa: Editorial Teorema, 1996. ARRUDA, Miguel. escultura / design / arquitetura. Lisboa: MUDE, 2013.

BARDI, Lina Bo. Tempos de Grossura: o design no impasse. São Paulo: Ed. Instituto Lina Bo e P. M. Bardi, 1994.

BHABHA, Homi K. The Location of Culture. New York: Routledge, 1994.

2 Maria Gabriela da Oliveira Fernandes Ferreira, https://letraaletra.pt/ e-mail: info@letraaletra.pt 
BORGES, Adélia. Design + Artesanato: o caminho brasileiro. São Paulo: Terceiro Nome, 2011.

CANANI, Aline. De Bonecas, Flores e Bordados: Investigações Antropológicas no Campo do Artesanato em Brasília. Tese de Doutoramento, Universidade de Brasília, 2008.

CUNCA, Raul. Design, identidade e produção local. i+Diseño - Revista científico-académica internacional de Innovación, Investigación y Desarrollo en Diseño. 14, ano XI, 2019. p.150-163.

CUNHA, Manuela Carneiro. Relações e dissensões entre saberes tradicionais e saber científico. p. 301-310. in Cunha, Manuela Carneiro. Cultura com aspas e outros ensaios. São Paulo: Cosac Naify, 2009.

DILNOT, Clive. The science of uncertainty: the potential contribution of design to knowledge in Doctoral education in design conference, Ohio: Ohio State University, 1998. Disponível em https://www.jiscmail.ac.uk/cgi-bin/filearea.cgi?LMGT1=PHD- DESIGN\&a=get\&f=/dilnot.rtf.

FREIRE, Paulo. Educação e mudança. Rio de Janeiro: Paz e Terra, 1988.

FREIRE, Paulo. Pedagogia do Oprimido. Rio de Janeiro: Paz e Terra, 2011.

GODOY, Adilda S. A pesquisa qualitativa e sua utilização em administração de empresas. Revista de Administração de Empresas, São Paulo, 35 (4), 1995. p.65-71.

INGOLD, Tim. The work of the imagination in the texture of the present. Texto da Conferência proferida na abertura do evento homónimo, promovido pelo PPCIS/ UERJ, nov., 2012.

LEITE, R. P. Modos de vida e produção artesanal: entre preservar e consumir in Sampaio, H. (org.). Olhares itinerantes: reflexões sobre artesanato e consumo de tradição. São Paulo: Artesanato Solidário, 2005.

KUBRUSLY, Maria Emilia e IMBROISI, Renato. Desenho de fibra: artesanato têxtil no Brasil. Rio de Janeiro: Senac Nacional, 2011.

MARGOLIN, Victor. Design e Risco de Mudança. Aveleda: Verso da História, 2014.

MARTINS, G. A. Manual para Elaboração de monografias e dissertações. São Paulo: Atlas, 1994.

MICELLI, Stefano. Futuro artegiano. I Grilli Marsilio Editora, 2011.

PAOLIELLO, C. Possible impacts when design meets its local dimension. Anais 7o SDS Simpósio Design Sustentável, 2019.

PAOLIELLO, C. Inovação Socioambiental no Design: Caso de Estudo do Designer Domingos Tótora. Convergências: Revista de Investigação e Ensino das Artes, 2018.

PAOLIELLO, C. Uma nova metodologia para o fomento das parcerias entre designers e artesãos - uma proposta de inovação social. Anais 6o Ergotrip Design, Aveiro, 2017

PAOLIELLO, C. A search for Brazilian Craft Identity. Anais 10th International Conferences on Design History and Studies, 2016.

PAPANEK, Victor. Diseñar para El Mundo Real: ecologia humana y cambio social. Madrid: H. Blume Ediciones, 1977.

NORMAN, Donald A. O design do dia a dia. Rio de Janeiro: Anfiteatro, 2006. 
RANCIĖRE, Jacques. O mestre ignorante - cinco lições sobre a emancipação intelectual. Belo Horizonte: Autêntica, 2002.

SANTOS, Boaventura de Sousa. (2002). Para uma sociologia das ausências e uma sociologia das emergências. Revista Crítica de Ciências Sociais,v (63), 2002. p. 237-280. Disponível em https://journals.openedition.org/rccs/1285

SENNETT, Richard. O artífice. Rio de Janeiro: Record, 2009

SENNETT, Richard. Juntos - Os rituais, os prazeres e a política da cooperação. Rio de Janeiro: Editora Record, 2012. 